\title{
Laboratory and Clinical Diagnosis of Human Cytomegalovirus Infection after Transplantation
}

\author{
DUAN Yan-ping (段艳平)，CHEN Xiu-zhu（陈秀珠），ZHANG Xin（张欣） \\ Institute of Virology \\ LIU Dun-gui (刘敦贵), XIA Sui-sheng (夏愁生) \\ Institute of Organ Transplantation, Tongii Medical University, Wuhan
}

\begin{abstract}
Summary: Urine and blood specimens from 32 recipients of allograft organ transplant were investigated for human cytomegalovirus (HCMV) by conventional cell culture, indirect immunofluorescent assay subsequent to the rapid cell culture and DNA-DNA hybridization. The results showed that the rapid cell culture technique might be the best method for rapid detection of active HCMV infection after transplantation because it possesses the advantages of simplicity, speediness, sensitiveness, and high reliability of detecting productive HCMV infection. The major symptoms were prolonged or intermittent fever unresponsive to antibiotics, dysfunction or loss of function of the transplanted organ, pulmonary infilitates and leukopenia. As our results suggested, reactivation of a latent infection appears to be the most probable etiologic factor contributing to HCMV infection after transplantation.
\end{abstract}

Key words: allograft organ transplantation, human cytomegalovirus, 1aboratory diagnosis, symptoms

Human cytomegalovirus (HCMV) infection after transplantation can impair the structure and the function of the grafted organ and enhance the risk of allograft rejection ${ }^{11}$, thereby often resulting in failure of transplantation and endangering the patient's life. Recently, much has been already reported in the literature abroad regarding this problem. However, little is known in the literature at home. The present study was undertaken to investigate $\mathrm{HCMV}$ infection after transplantation in 32 recipients of organ transplant by laboratory methods and clinical observation.

\section{PATIENTS AND METHODS}

1. Patients and immunosuppressive dgents 
32 recipients of allograft organ transplant, including 28 with renal, 2 with pancreatic and 2 with spleenic allograft were treated at the Department of Transplantation, Tongji Hospital, Tongji Medical University, from 1986 to 1987 . In all these patients the immunosuppressive protocol used consisted of antilymphocyte globulin (ALG, 20 $\mathrm{mg} / \mathrm{kg} \cdot \mathrm{d}$ ), azathioprine ( $3 \mathrm{mg} / \mathrm{kg} \cdot \mathrm{d}$ ) and prednisone (from $2 \mathrm{mg} / \mathrm{kg} \cdot \mathrm{d}$ to $1 \mathrm{mg} / \mathrm{kg} \cdot \mathrm{d}$ ) for about 10 days following transplantation. After the grafted organ regained its normal function, cyclosporine $A$ (CsA), azathioprine and prednisone were given as the maintenance immunosuppressive regimen. Besides the above mentioned drugs, mouse anti- $\mathbf{T}_{3}$, $T$, human lymphocyte monoclonal antibodies (Wuhan Institute of Biological Products) were given to 3 of the patients.

2. Collection and pretreatment of specimens

$4 \mathrm{ml}$ heparinized blood and $20 \mathrm{ml}$ urine treated with penicillin $(1000 \mathrm{U} /$ $\mathrm{ml})$ and streptomycin $(1000 \mathrm{U} / \mathrm{ml})$ were collected into sterile sample bottles from each patient beginning at the operation day or one week after transplantation, kept at $-4^{\circ} \mathrm{C}$, and transported to the laboratory. After separation from the blood by the Ficoll-Hypaque gradient method, the plasma was stored at $-80^{\circ} \mathrm{C}$ until use, and the buffy coat leukocytes were used for inducing interleukin 2 .

The $\mathrm{pH}$ of a $10 \mathrm{ml}$ urine specimen was adjusted to 7.0 to 7.2 with $3 \mathrm{~N}$ sodium hydroxide or hydrochloride, fetal calf serum (FCS) was added to the concentration of $10 \%$, then the specimen was centrifuged for $30 \mathrm{~min}$ at 1000 $g$ to remove cells and crystals.

Samples were obtained from each of the patients at intervals, in general 3 to 5 times per person during this study.

3 . Conventional virus isolation in cell culture

An aliquot $(1 \mathrm{ml})$ of the treated urine specimen was inoculated into each of 4 tissue culture bottles containing grown monolayer of human embryonic lung cells. The urine was removed after $1 \mathrm{~h}$ absorption at $37^{\circ} \mathrm{C}$ and replaced by Eagle's minimal essential medium (MEM, $1.5 \mathrm{ml}$ per bottle) containing $10 \%$ FCS and antibiotics. The inoculated cells were cultured in rotating condition at $37^{\circ} \mathrm{C}$. The media in the bottle were replaced by MEM containing $5 \%$ FCS 2 days later and routinely refreshed every one week thereafter. The bottles were refed (i.e., the inoculated human embryonic lung cells were trypsinized, subsequently mixed with fresh trypsinized cells and continuously cultured) every 2 weeks with MEM containing $5 \%$ FCS and observed for the development of cytopathic effects every other day for 2 months. HCMV isolate was identified on the basis of the following characteristics: a) slowly developing typical cytopathic effects in human embryonic lung cells but no cytopathic effects in Vero cells; b) the supernatant prepared from the cy topathic effect cells being positive for HCMV antigen detected by ELISA' ${ }^{2 !}$.

4. Indirect immunofluorescent assay in rapid cell culture

The method reported by Alpert et al' ${ }^{3}$ with slight modifications was used. Human embryonic lung cells were seeded into culture vials, each containing a $6 \times 20 \mathrm{~mm}$ cover slip, and grown in the previously described growth medium. $1 \mathrm{ml}$ of the treated urine was inoculated into each of the 6 culture vials by the above mentioned method. The cover slips were taken out $48 \mathrm{~h}$ and 6 days after inoculation, fixed with cold acetone overnight at $-20^{\circ} \mathrm{C}$ and mounted on a glass slide with Canada balsam. The cover slips on the glass slides were incubated for $90 \mathrm{~min}$ at $37^{\circ} \mathrm{C}$ with 150 $\mu l$ of mouse anti-HCMV monoclonal antibody $\mathrm{McAb}-20 \mathrm{k} \quad(1: 800$; kindly provided by Prof. Wu SM, Wuhan Institute of Virology) and sera positive for anti-HCMV IgG (1:100; from the ELISA kit, Beijing Institute of Viro- 
$\log y$ ), respectively. The cover slips were washed 3 times, for $5 \mathrm{~min}$ each time, with phosphate-buffered saline (PBS), pH 8.0. Fluorescein (FITC)conjugated rabbit antibody to BALB/C mouse IgG $(1: 16$; Beijing Institute of Biological Products) and sheep antibody to human IgG ( $1: 12$; Shanghai Institute of Biological Products) were then added respectively, the specimens were incubated for $60 \mathrm{~min}$ at $37^{\circ} \mathrm{C}$ and washed 3 times for 5 min each time with PBS, pH 8.0. The cover slips were covered by $25 \%$ glycerol in PBS, pH 8.0, and then a cover slide was put on each of the slips. The slips were viewed under a fluorescence microscope (Nikon, Japan) illuminated with a super pressure mercury lamp at $250 \times$ or $400 \times$.

Control tests of cells positive or negative for HCMV AD169 strain and the conjugated antibodies were performed at the same time.

Based on our preexperimental results and previous report ${ }^{\prime 3}$, a specimen with at least 2 typically fluorescent nuclei on one cover slip, or one fluorescent nucleus on each of the 2 duplicate cover slips was considered positive for $\mathrm{HCMV}$.

5. Detection of HCMV DNA from the specimens by DNA-DNA dot blot hybridization

The proceedings were performed as described previously' ${ }^{4}$.

6. Measurement of the titer of anti-HCMV IgG in plasma by ELISA

Performed according to the introduction of ELISA kit, each of the plasma specimens was diluted from $1: 20$ to 1:1280 in PBS at pH 7.4. Absorbance and $O D$ value were read at $492 \mathrm{~nm}$ on automated ELISA reader EAR-400 (Austria). Specific absorbance was calculated by averaging the $O D$ values in the duplicate wells and dividing them by the average $O D$ values of the two control wells, that is $P / N$. A dilution with $P / N \geqslant 2.1$ was taken as positive for HCMV IgG, and the highest one was considered as the final titer.

\section{RESULTS}

1. Results of conventional isolation in cell culture

Eleven out of 28 recipients of allograft organ transplant, 9 of 24 with renal transplant were positive for HCMV. The samples of 4 renal allograft recipients were frequently contaminated and failed to be continuously cultured. The incidence of active HCMV infection was $39.28 \%$ and $37.5 \%$, respectively. 2 pancreatic allograft recipients were both positive, while 2 spleenic allograft recipients were both negative. Isolation of HCMV required 14 to 48 days, with a mean of 29 days. The onset of active HCMV infection occurred 12 to 266 days after transplantation, with an average of 84.5 days.

2. Results of indirect immunofluorescent assay (IIFA) in the rapid cell culture

Positivity of IIFA by using $\mathrm{McAb}-20 \mathrm{k}$ was exhibited by bright green fluorescence in nuclei or spots inside cellular nuclei, while positivity of IIFA by using sera for anti-HCMV IgG showed such signs in cytoplasm region. By the former assay 9 of 28 recipients of allograft were positive for HCMV antigen $48 \mathrm{~h}$ following transplantation, and each of them later developed typical cytopathic effect. Two of the remaining 19 negative patients were identified as HCMV-positive by virus isolation in routine cell culture. By the latter, 11 of 28 organ transplant recipients were positive 6 days after transplantation. All of the positive and one of the negative cases were positive for $\mathrm{HCMV}$ as shown by virus isolation. Comparison of the two IIFA in the rapid cell culture with conventional isolation in cell culture is shown in table 1 , fig. 1 . No cross-reaction with HSV-I and HSV-I was found either in $\mathrm{McAb}-20 \mathrm{k}$ or in IgG positive sera.

3. Results of dot blot hybridization 15 of 32 allograft organ transplant recipients and 13 of 28 renal allograft 


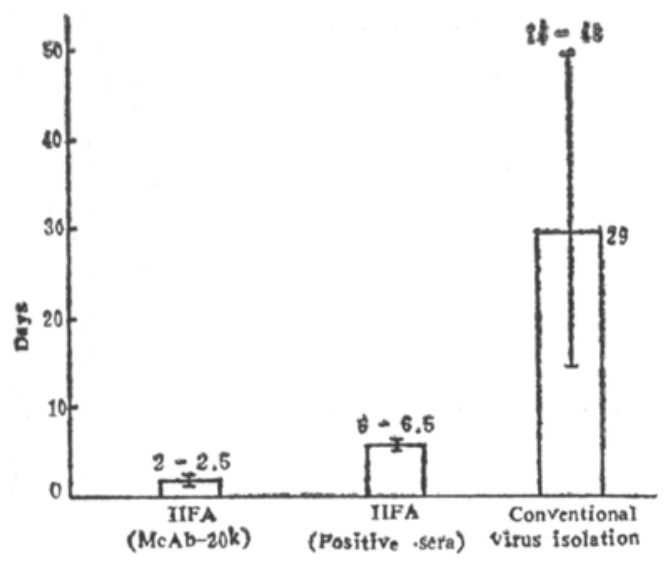

Fig.1. Comparison of the detecting time of the three methods.

recipients were positive in blood specimens, the positive rate being $46.8 \%$ and $46.45 \%$ respectively. 13 of 32 recipients of allograft organ transplant and
12 of 28 renal allograft recipients were positive in urine samples, with a rate of $40.63 \%$ and $42.86 \%$ respectively.

4. ELISA results

As table 2 indicates, the positive rate of anti-HCMV IgG in plasma from the organ transplant recipients at the operating day or one week later was close to that from normal blood donors, although geometric mean titer was lower in the former than in the latter. The plasma from all organ transplant recipients with positive $\mathrm{HCMV}$ isolation was positive for IgG, their geometric mean titer was lower than that of recipients with negative isolation. 2 weeks later 2 patients with active HCMV infection had a four fold or gremter increase in IgG, the others were kept at the former level or tended to be lower.

5. Clinical findings

As shown in table 3 , prolonged or

Table1. Comparison of results from two IIFA procedures with those of conventional virus isolation

\begin{tabular}{|c|c|c|c|c|c|}
\hline \multirow{2}{*}{$\begin{array}{l}\text { Conventional } \\
\text { virus } \\
\text { isolation }\end{array}$} & \multicolumn{2}{|c|}{$\begin{array}{l}\text { IIFA by using } \\
\text { McAb-20k }\end{array}$} & \multicolumn{2}{|c|}{$\begin{array}{l}\text { IIFA by using } \\
\text { positive serab }\end{array}$} & \multirow{2}{*}{ Total } \\
\hline & $(+)$ & $(-)$ & $(+)$ & $(-)$ & \\
\hline$(+)$ & 9 & 2 & 10 & 1 & 11 \\
\hline$(-)$ & 0 & 17 & 1 & 16 & 17 \\
\hline Total & 9 & 19 & 11 & 17 & 28 \\
\hline
\end{tabular}

Sensitivity: a ,81.8\%; b,90.9\%

Specificity: a, $100 \% ; b, 94.12 \%$

Table2. Comparison of the geometrical mean titer of anti-HCMV IgG in the plasma from normal people and organ transplant recipients, with HCMV isolation positive and negative.

\begin{tabular}{cccl}
\hline Group & No. & Positive rate & GMT \\
\hline OTRs & 28 & $90.32 \%^{\mathrm{a}}$ & $1: 150^{+}$ \\
HCMV(+) & 11 & $100 \%^{\mathrm{b}}$ & $1: 86^{*}$ \\
HCMV(-) & 17 & $82.36 \%^{\mathrm{b}}$ & $1: 120^{*}$ \\
Normal people & 15 & $80 \%^{\mathrm{a}}$ & $1: 120^{+}$ \\
\hline
\end{tabular}

U-test: a,b both $P>0.05$

$t$-test:,$+ P>0.01 ; *, P<0.05$ 


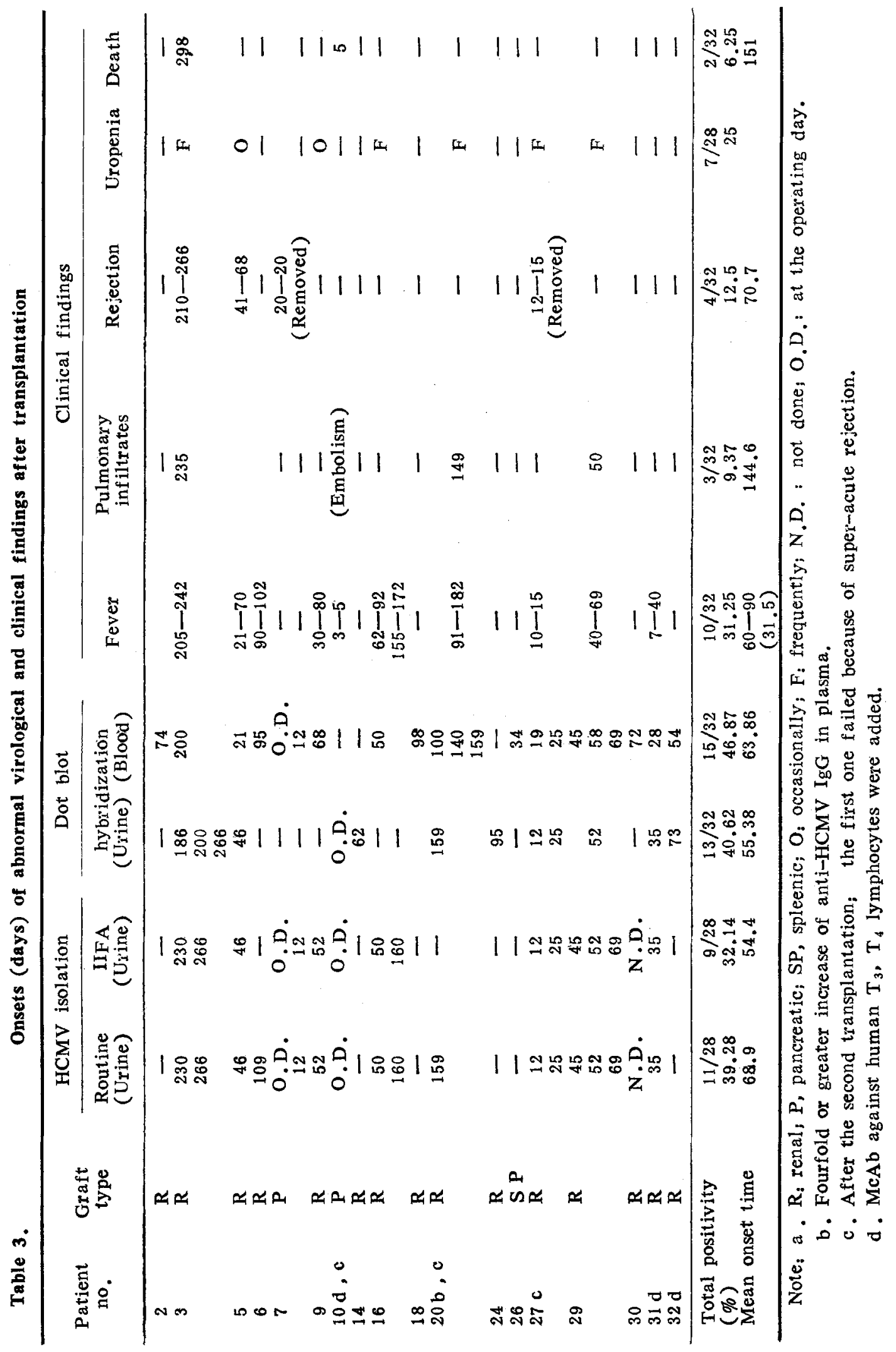


intermittent fever occurred in 10 $(90.9 \%)$ of the 11 patients with active HCMV infection or viruria usually 1 to 3 months after transplantation. The temperature frequently reached 38 to $39 \mathrm{C}$ lasting for as long as 3 to 4 weeks, with a mean of 32 days. Active HCMV infection was followed by onset of fever within 25 days in 9 of these 10 patients and preceded within 2 weeks in one patient. The-fever was not related to ALG therapy and showed no response to antibiotics. Of the 9 patients 3 developed pulmonary patchy interstitial or patchy alveolar infiltrates, especially in the low lobules, demonstrated by $\mathbf{X}$-rays within 10 days after onset of active HCMV infection, and one of the cases died later. One pancreatic allograft recipient died of pulmonary infarct after 5 days of onset of active HCMV infection during the second transplantation. Episodes of allograft rejection occurred in 4 patients within 3 weeks after active HCMV infection. The grafted organs of one pancreatic and one renal allograft recipients were removed because of failure of function and their biopsy specimens demonstrating histopathological evidence of allograft rejection. The leukocyte count fell rapidly in most organ transplant recipients with active HCMV infection. Some of them even developed serious leukopenia $\left(<2000\right.$ cells $\left./ \mathrm{mm}^{3}\right)$. Uropenia frequently occurred in renal allograft recipients with active HCMV infection. The 17 recipients with allograft transplant with negative HCMV isolation, including some cases with positivity for dot blot hybridization in urine or blood samples, occasionally developed fever after transplantation. But the fever was temporal and could be stopped by removing ALG or adding antibiotics. No pulmonary infiltrates were observed in the negative patients.

\section{DISCUSSION}

Conventional virus isolation in cell culture was considered to be the best method for detecting HCMV in- fection, but its cumbersome and timeconsuming procedure due to slow growth of the virus made it unsuitable for rapid and early detection of HCMV. As a recently developed technique, with high sensitivity and strong specificity for diagnosis of viral infection by detecting viral genome, nucleic acid hybridization was thought of as a promising rapid detection method ${ }^{5}$. However, the necessity to use expensive radiolabelled reagents and the short half-life of the labelled probe prevent widespread use of this method. The results obtained by this method did not unmistakably indicate an active infection. This notion was supported by our experimental results. Therefore, it will not be very useful for $\mathrm{HCMV}$ rapid detection for the time being. Technique of determination of specific IgM was not available for rapid detection of $\mathrm{HCMV}$ in immunosuppressive patients ${ }^{\circ}$. The method described here combines the advantages of the reliable, sensitive cell culture with those of the simple, specific indirect immunofluorescent assay. Active HCMV infection was diagnosed specifically and sensitively by use of monoclonal antibody which detects early nuclear antigens in inoculated human embryonic lung cells. The results were available to the clinician $48 \mathrm{~h}$ after inoculation of the specimens and much earlier than those of the cell culture, which required an average of 29 days in this study. Rapidity of this method was very useful for early differentiation of active HCMV infection in allograft rejection and was considered to be the best method for rapid early diagnosis of HCMV infection in recipients of allograft transplants. Use of monoclonal antibodies against HCMV immediately to early antigens would give much earlier results, 16 to $24 \mathrm{~h}$ after inoculation ${ }^{|7|}$. A satisfactory result might be obtained if hyperimmune anti-HCMV IgG positive sera were used without monoclonal antibodies.

The results obtained in our study 
support the view that HCMV might be latent in leukocytes and could be transported into each organ of the body, in particular to the lungs, kidneys and liver ${ }^{8 !}$. The clinical complications in the patients with active HCMV infection consisted of fever mostly lasting or intermittent and unresponsive to antibiotics, dysfunction of the grafted organ, leukopenia and even widespread pulmonary infiltrates.

HCMV infection after transplantation was suggested to be mostly the result of reactivation of the previously latent virus infection since the positive rate of anti-HCMV IgG in the plasma from recipients of allograft organ transplant was as high as $93 \%$ at the operating day, and $100 \%$ in the patients with active HCMV infection after and before transplantation. It was found that humoral immunity and interferon system of the transplant recipients were inhibited, and that the more the patients were immunosuppressed the more they tended to reactivate latent infection. Therefore, it was held that suppression of immunological functions might be one of the causes for reactivation. It might be an active step to prevent or relieve HCMV infection if immunoglobulins were given and the doses of the immunosuppressors were decreased. In view of the possible latent virus in the seemingly healthy persons such as blood donors, whose positivity of anti-HCMV IgG is $80 \%$, great care must be taken in the selection of the graft or blood donors for transplantation to avoid the potential primary HCMV infection after transplantation in the recipients whose specific IgG against HCMV was negative before transplant operation.

\section{Acknowledgement}

We greatly appreciate the technical assistance of $\mathrm{Mr}$. ZHOU Ru-lin and $\mathrm{Mr}$. XU Hui-tang in our virological 1aboratory and thank the nurses in the Department of Organ Transplantation, Tongji Hospital, for their assistance in collecting the samples.

\section{REFERENCES}

1. Glenn J, et al. Cytomegalovirus infection following renal transplantation. T:ansplantation 1984;38:506-11.

2. Mckeating $J_{A}$, et al. Detection of cytomegalovirus in uxine samples by enzymelinked immunoabsorbent assay. J Med Virol 1985; 16:367-73.

3. Alpert G, et a1. Rapid detection of human cytomegalovirus in the urines of humans. J Infect Dis 1985;152:631-3.

4. Zhang $X$, et al. DNA probe technique for diagnosis of human cytomegalovirus infection. $J$ Tongji Med Univ 1989;9: 170-3.

5. Spector SA, et al. Detection of human cytomegalovirus in clinical specimens by DNA-DNA hybridization. J Infect Dis $1984 ; 150: 121-6$.

6. Panjwani DD, et al. Virological and serological diagnosis of cytomegalovirus infection in bone marrow allograft recipients. J Med Virol 1985:16:357-65.

7. Thiele GM, et al. Rapid detection of cytomegalovirus by tissue culture, centrifugation and immunofluorescence with a monocional antibody to an early ant igen. J Virol Methods 1987;16:327-38.

8. Schier RD, et al. Detection of HCMV in lymphocytes in a natural infection. Science $1985 ; 230: 1048-57$. 